\title{
Structural, neuronal, and functional adaptive changes in atrophic rat ileum
}

\author{
K M Ekelund, E Ekblad
}

\begin{abstract}
Background-Inactivity of the gut leads to atrophic changes of which little is known. Aims-To investigate structural, neuronal, and functional changes occurring in bypassed rat ileum.

Methods-Morphometry was used to characterise the atrophic changes. The numbers of enteric neurones, their expression of neurotransmitters, and the presence of interstitial cells of Cajal were studied using immunocytochemistry and in situ hybridisation. Motor activity was studied in vitro.
\end{abstract}

Results-Adaptive changes in bypassed ileum include atrophy and remodelling of the gut wall. The total numbers of submucous and myenteric neurones per unit length increased one and four weeks after bypass but were identical to sham operated intestine 10 weeks after bypass. Neurones expressing vasoactive intestinal peptide, neuropeptide $Y$, or pituitary adenylate cyclase activating peptide decreased gradually in number in bypassed ileum. Nitric oxide synthase expressing neurones were increased, particularly in the myenteric ganglia. No change in the frequency and distribution of interstitial cells of Cajal was noted. The contractile response elicited by electrical stimulation of sham operated ileum consisted of a fast cholinergic twitch followed by a slower non-adrenergic, non-cholinergic contraction. In the bypassed ileum an identical biphasic contraction was elicited; however, the entire response was nonadrenergic, non-cholinergic. The relaxatory response to electrical stimulation in sham operated ileum was nitric oxide mediated; after bypass it was nonnitrergic.

Conclusions-Notable atrophic changes were seen in the rat ileum after bypass. The enteric nervous system reacted with neuronal cell death and plasticity in terms of release and expression of neurotransmitters.

(Gut 1999;45:236-245)

Keywords: neuronal plasticity; enteric nerves; interstitial cells of Cajal; atrophy; neuropeptides; nitric oxide

Changes in activity lead to both functional and structural adaptive adjustments in most organ systems, including the gastrointestinal tract (for reviews see Dowling ${ }^{1}$ and Wolvekamp and colleagues $^{2}$ ). In the intestine hypertrophy can be experimentally induced by partial obstruction of the ileum of rat or guinea pig. ${ }^{3-5}$ This leads to a notable thickening of the smooth muscle in the proximally located segment as well as neoformation of connective tissue matrix, neoangionesis, and hypertrophy of the enteric neurones. ${ }^{34}$ In addition, several neuronal populations in the hypertrophic ileum of rat change their expression of neuromessengers, and the number of c-kit expressing interstitial cells of Cajal (ICC) notably decreases. ${ }^{5}$ Functionally, the peristaltic activity in the hypertrophic segment is as effective as in control intestine. ${ }^{6}$ Gut hypertrophy is also seen after extensive bowel resection. The remaining intestine evolves a notable mucosal hypertrophy. This adaptive response is essential in order to overcome malabsorption and is highly dependent on enteral nutrition (for a review see Vanderhoof and Langnas ${ }^{7}$ ).

Structural and functional changes in atrophic intestine are less well characterised. Atrophy accompanies conditions when enteral nutrition is excluded, such as total parenteral nutrition. ${ }^{8}$ The distal colon after diverting colostomy in the rat shows atrophic changes in both the mucosa and smooth muscle. ${ }^{9}$ No information on the adaptive responses of the enteric nervous system (ENS) or the interstitial cells of Cajal (ICC) in atrophic intestine is available. The development and survival of autonomic (and sensory) neurones are influenced by target derived neurotrophic factors and neurodegeneration has been suggested to result from changes in the interactions between neurones and their targets. Thus, neuronal survival may depend on the supply of target derived neurotrophic factors, actions of components of the extracellular matrix, and changes in the neuronal responsiveness to these factors (for a review see Gavazzi and Cowen ${ }^{10}$ ). Whether intestinal atrophic changes influence the survival of the enteric neurones or induce any changes in their function or expression of neurotransmitters is unknown.

The aims of the present study were: (1) To examine the atrophic changes by morphometric analysis of the circumference, the height of

Abbreviations used in this paper: ATP, adenosine triphosphate; CGRP, calcitonin gene related peptide; EFS, electric field stimulation; ENS, enteric nervous system; EtBr, ethidium bromide; GRP, gastrin releasing peptide; ICC, interstitial cells of Cajal; L-NAME, L-N-nitro-arginine methyl ester; NADPH, nicotinamide adenine dinucleotide phosphate; NANC, non-adrenergic, non-cholinergic; nNOS, neuronal nitric oxide synthase; NO, nitric oxide; NPY, neuropeptide Y; PACAP, pituitary adenylate cyclase activating peptide; SP, substance P; TTX, tetrodotoxin; VIP, vasoactive intestinal peptide.
Dr Ekblad

Accepted for publication 2 February 1999 


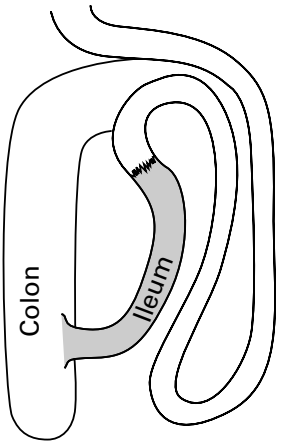

Sham

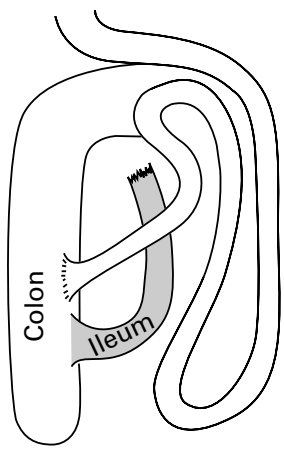

Bypass
Figure 1 Schematic outline of the surgical procedures used.

the whole wall, and the different layers within the gut wall in bypassed and sham operated distal ileum of the rat. (2) To elucidate possible changes in the number of enteric neurones and their expression of neurotransmitters by using histochemistry, immunocytochemistry, and in situ hybridisation. (3) To study the presence of ICC within the bypassed ileal segment. (4) To characterise electrically induced motor responses of the longitudinal smooth muscle layers with adherent myenteric ganglia from bypassed and sham operated ileum in vitro.

\section{Materials and methods}

ANIMALS, SURGICAL PROCEDURES, AND TISSUE PROCESSING

Adult female Spraque-Dawley rats (180-200 g, $\mathrm{n}=64$ ) were used. The distal ileum was bypassed by anastomosis of proximal ileum and colon; sham operated rats served as controls. The animals were anaesthetised with chloral hydrate $(300 \mathrm{mg} / \mathrm{kg})$ given intraperitoneally. Via an abdominal midline incision the distal ileum was divided $10 \mathrm{~cm}$ from the ileocaecal valve and either transposed to the proximal colon approximately $1 \mathrm{~cm}$ from caecum, thereby creating a bypassed defunctional distal ileum, or resutured (sham operation) (fig 1). Operated rats were housed with free access to standard rat pellet food and water.

Postoperatively the animals were monitored daily with regard to weight and general well being. Sham operated rats were killed after one week and rats with bypassed ileum were killed one, four, or 10 weeks postoperatively. Specimens from distal ileum were tested for motor activity in vitro (described below) or processed for light microscopical examination, immunocytochemistry, and in situ hybridisation. For the morphological analysis, distal ileum from bypassed ( $n=6$ in each time group) and sham operated $(n=6)$ rats was opened along the mesenteric border and pinned flat, without stretching, on pieces of balsa wood. The specimens were fixed overnight in a mixture of $2 \%$ formaldehyde and $0.2 \%$ picric acid in phosphate buffer $(\mathrm{pH} 7.2)$ followed by thorough rinsing in Tyrode's solution containing 10\% sucrose. Whole wall specimens, approximately $10 \mathrm{~mm}$ long, were then frozen on dry ice and cut in a cryostat to a thickness of $10 \mu \mathrm{m}$. Sections were placed on chrome alum coated slides and processed for haematoxylin and eosin staining, NADPH diaphorase histochemistry, immunocytochemistry, in situ hybridisation, or ethidium bromide (EtBr) staining. The procedures were approved by the Animal Ethics Committee, Lund University.

\section{IMMUNOCYTOCHEMISTRY}

Previously characterised neuronal nitric oxide synthase (nNOS), neuropeptide Y (NPY), vasoactive intestinal peptide (VIP), substance $\mathrm{P}$ (SP), galanin, pituitary adenylate cyclase activating peptide (PACAP), calcitonin gene related peptide (CGRP), and gastrin releasing peptide (GRP) antisera raised in rabbits (table 1) were used to show the various neuronal populations. ICC were shown using an affinity purified polyclonal rabbit antiserum raised against a synthetic peptide corresponding to amino acid residues $958-976$ within the $\mathrm{C}$ terminal domain of the human c-kit receptor (Santa Cruz Biotechnology, Santa Cruz, California, USA). The antiserum is known to cross react with the tyrosine kinase receptor, c-kit, expressed by ICC. ${ }^{5}$ The site of the antigenantibody reaction was visualised by fluorescein isothiocyanate conjugated antibodies to rabbit IgG raised in pigs (Dako, Copenhagen, Denmark). For controls, antisera (except the c-kit receptor antibodies) that had been inactivated by the addition of an excess amount of antigen (10-100 $\mu \mathrm{g}$ of synthetic peptide per ml diluted antiserum) were used. In addition each peptide

Table 1 Details of antisera

\begin{tabular}{|c|c|c|c|c|c|}
\hline Antigen & Code & Raised against & $\begin{array}{l}\text { Working } \\
\text { dilution }\end{array}$ & Source & Reference \\
\hline CGRP & 8427 & Synthetic CGRP & $1 / 320$ & $\begin{array}{l}\text { Euro-Diagnostica AB, Malmö, } \\
\text { Sweden }\end{array}$ & 11 \\
\hline Galanin & 8416 & Synthetic porcine galanin & $1 / 320$ & $\begin{array}{l}\text { Euro-Diagnostica AB, Malmö, } \\
\text { Sweden }\end{array}$ & 12 \\
\hline GRP & R-6902 & Synthetic porcine GRP & $1 / 320$ & $\begin{array}{l}\text { Professor N Yanaihara, Shizouka, } \\
\text { Japan }\end{array}$ & 12 \\
\hline nNOS & 9223 & $\begin{array}{l}\text { Synthetic C-term fragment of rat } \\
\text { cerebellar NOS }\end{array}$ & $1 / 1280$ & $\begin{array}{l}\text { Euro-Diagnostica AB, Malmö, } \\
\text { Sweden }\end{array}$ & 13 \\
\hline NPY & 8404 & Synthetic porcine NPY & $1 / 320$ & $\begin{array}{l}\text { Euro-Diagnostica AB, Malmö, } \\
\text { Sweden }\end{array}$ & 12 \\
\hline PACAP & $88121-3$ & Pure ovine PACAP-27 & $1 / 640$ & $\begin{array}{l}\text { Professor A Arimura, Louisiana, } \\
\text { USA }\end{array}$ & 14 \\
\hline SP & SP8 & Synthetic bovine SP & $1 / 320$ & $\begin{array}{l}\text { Professor P C Emson, } \\
\text { Cambridge, UK }\end{array}$ & 11 \\
\hline VIP & 7852 & Natural porcine VIP & $1 / 640$ & $\begin{array}{l}\text { Euro-Diagnostica AB, Malmö, } \\
\text { Sweden }\end{array}$ & 11 \\
\hline
\end{tabular}


antibody was tested for cross reactivity with the other peptides examined. Cross reactivity with still other peptides or proteins cannot be excluded. It is appropriate, therefore, to refer to the immunoreactive material as VIP-like, NPY-like, and so on. For simplicity, however, the shorter terms are used in the following.

IN SITU HYBRIDISATION

For the detection of nNOS mRNA, a 30 mer oligodeoxyribonucleotide probe complementary to the sequence $77-106$ of rat cerebellar NOS mRNA ${ }^{15}$ was used (Biomolecular Resource Facility, University of Lund, Sweden). For the detection of VIP mRNA a 29 mer oligoprobe complementary to the nucleotides 347-375 in rat VIP mRNA $^{16}$ was used (Du Pont Scandinavia AB, Sweden). NPY mRNA was detected using a 36 mer oligoprobe complementary to the nucleotides $266-301$ in rat NPY mRNA ${ }^{17}$ (Biomolecular Resource Facility). Galanin mRNA was detected using a 30 mer oligoprobe complementary to nucleotides $275-304$ in rat galanin $\mathrm{mRNA}^{18}$ (Biomolecular Resource Facility, University of Lund, Sweden). CGRP mRNA was detected using a 30 mer oligoprobe complementary to nucleotides 3837-3868 in rat $\alpha$ CGRP (NEN duPont, Stockholm, Sweden). The nNOS, galanin,VIP, and NPY mRNA probes have previously been used in in situ hybridisation on enteric neurones. ${ }^{519}$ The CGRP probe has been used to show sensory neurones. ${ }^{20}$ The probes were $3^{\prime}$ endtailed with ${ }^{35} \mathrm{~S}$-dATP by use of terminal transferase (both supplied by NEN, DuPont, Stockholm, Sweden), yielding a specific activity of approximately $2 \times 10^{9} \mathrm{cpm} / \mu \mathrm{g}$. The hybridisation protocol has previously been described in detail. ${ }^{20}$ Briefly, after clearing in chloroform, the sections were acetylated and hybridised with the probes $(1 \mathrm{pmol} / \mathrm{ml})$ overnight at $37^{\circ} \mathrm{C}$. The slides were washed $(1 \times \mathrm{SSC}, 4 \times 15 \mathrm{~min}-$ utes, $55^{\circ} \mathrm{C}$ ), dehydrated, and dipped in emulsion (Ilford K5). Exposure times ranged between three and four weeks, after which the slides were developed in Kodak D-19. For control purposes, hybridisation was also performed after incubation in RNAse A $(45 \mu \mathrm{g} / \mathrm{ml}$, Sigma, St Louis, Missouri, USA; 30 minutes at $37^{\circ} \mathrm{C}$ ) or in the presence of a 100 -fold excess of unlabelled probe in the hybridisation buffer. In the control experiments, autoradiographic labelling of enteric neurones was not obtained.

\section{NADPH HISTOCHEMISTRY}

NADPH diaphorase activity was rendered visible by incubation of cryostat sections for 45 minutes in $0.1 \mathrm{M}$ Tris- $\mathrm{HCl}(\mathrm{pH} 7.2)$ containing $1 \mathrm{mM}$ NADPH (Sigma, St Louis, Missouri, USA), $0.2 \%$ Triton $\mathrm{X}-100$ at $37^{\circ} \mathrm{C}$ followed by washing in Tris- $\mathrm{HCl}$ (modified from Hope and colleagues ${ }^{21}$ ).

\section{EtBr STAINING}

Counter staining using $0.1 \%$ of $\mathrm{EtBr}$ in Tris- $\mathrm{HCl}$ was used in order to visualise all nerve cell bodies. ${ }^{52}$ Since atrophic changes in the bypassed ileal segments may cause reduced synthesis of various neuronal substances immunocytochemical detection of general neuro- nal markers was avoided due to the risk of obtaining false low neuronal cell counts.

CELL COUNTING

Immunoreactive, NADPH positive, $\mathrm{EtBr}$ stained or autoradiographically labelled (mRNA containing) nerve cell bodies in submucous and myenteric ganglia were counted per visual field $(1.2 \mathrm{~mm})$ in longitudinally cut whole wall sections from sham operated $(n=5)$ and bypassed $(n=15$, five in each time group) ileum. Each section was approximately $10 \mathrm{~mm}$ long and from each animal three sections cut at different depths were analysed. Data are expressed as mean (SEM). Statistical evaluation was by Student's $t$ test.

MORPHOMETRIC ANALYSIS

Automated measurements of the thickness of the mucosa, submucosa, muscular coat, and the whole ileal wall, were performed using a computerised image analysing system (Leica, Q500MC). Measurements were performed on longitudinally cut haematoxylin-eosin stained sections of ileum from sham operated rats and rats one, four, or 10 weeks after bypass $(n=3$ in each group). The height of each layer was defined using a binary cursor; the average of 30 measurements was used. The circumference of the distal ileum from sham operated $(n=6)$ and bypassed rats ( $n=6$ in each time group) was measured using a ruler after the distal ileum had been cut open and placed on a moist filter paper without stretching. Data are expressed as mean (SEM). Statistical evaluation was by Student's $t$ test.

\section{IN VITRO EXPERIMENTS ON MOTOR ACTIVITY}

INDUCED BY ELECTRIC FIELD STIMULATION

Ten sham operated and 30 (10 in each time group) bypassed rats were used. The animals were anaesthetised in vaporised diethylether and sacrificed by bleeding. The ileum was dissected out and placed in ice cold Krebs' solution with the following composition (in $\mathrm{mM}$ ): $\mathrm{NaCl} 133.0, \mathrm{KCl} 4.7, \mathrm{CaCl}_{2} \times 2 \mathrm{H}_{2} \mathrm{O} 2.5$, $\mathrm{MgCl}_{2} 1.0, \mathrm{NaHCO}_{3} 16.3, \mathrm{NaH}_{2} \mathrm{PO}_{4} 1.4$, and glucose 7.8 . Strips (10 mm long) from longitudinal smooth muscle with adherent myenteric ganglia were dissected out using a dissection microscope. The strips were mounted in organ baths containing $5 \mathrm{ml}$ of Krebs' solution aerated with a mixture of $5 \% \mathrm{CO}_{2}$ and $95 \% \mathrm{O}_{2}$ and continuously recorded for isometric tension with a Grass FTO3C force displacement transducer and registered on a Grass model $79 \mathrm{D}$ polygraph. Bath temperature was maintained thermostatically at $37^{\circ} \mathrm{C}$ and the $\mathrm{pH}$ was kept around 7.40 (range 7.35-7.45). The strips were given an initial passive load of $20-25 \mathrm{mN}$ and allowed to equilibrate for one hour before experimentation started. During this period the preparations gradually relaxed and the basal tension stabilised at 3-5 mN. Rhythmic spontaneous contractions with varying amplitude developed in all preparations. Platinum electrodes $(0.5 \mathrm{~mm}$ in diameter and $10 \mathrm{~mm}$ apart) were mounted on both sides of the muscle strip. The electrodes were connected to a Grass S4C stimulator for field stimulation with 

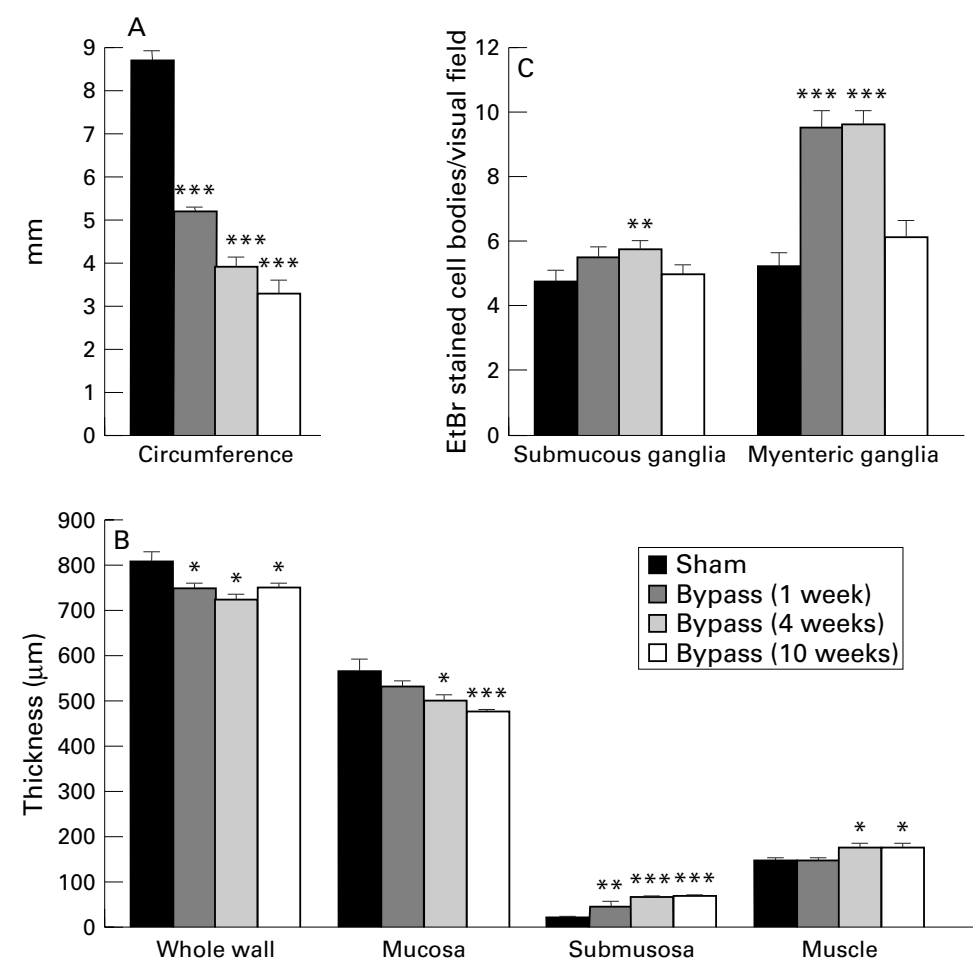

Figure 2 Measurements on the circumference $(A)$ and thickness of the whole wall, mucosa, submucosa, and muscle layers (B) in rat ileum, sham operated and bypassed for one, four, or 10 weeks. (C) Total numbers of submucous and myenteric nerve cell bodies (as estimated by EtBr staining) per visual field in longitudinally cut sections from sham operated and bypassed rats. Mean (SEM). ${ }^{\star} p<0.05,{ }^{\star *} p<0.01,{ }^{\star}{ }^{*} p<0.001$ compared with sham operated. the circumference of the ileum was $60 \%$, after four weeks $45 \%$, and after 10 weeks of bypass $40 \%$ of that of the sham operated animals.

At one week after being bypassed the thickness of the whole ileal wall was slightly reduced (approximately $90 \%$ that of the sham operated; fig 2B). No further reduction was seen at four or 10 weeks (fig 2B). The height of the mucosa was reduced throughout the observation period (to approximately $80 \%$ of that of the sham operated after 10 weeks of bypass) while the submucosa increased in thickness (fig 2B). One week after bypass the thickness of the submucosa was doubled and after four weeks three times that of sham operated. From four to 10 weeks after bypass no further increase in submucosal thickness could be noted. The thickness of the muscle layers was largely unaffected; a slight thickening could be noted in the bypassed ileal segments at four and 10 weeks postoperatively (fig $2 \mathrm{~B}$ ).

\section{IMMUNOCYTOCHEMISTRY AND IN SITU}

HYBRIDISATION

With the exception of the c-kit antiserum, a marker for the ICC, all antibodies used showed immunoreactive nerve fibres and cell bodies in both sham operated and bypassed ileum; the VIP and nNOS containing neuronal populations are illustrated in fig 3. Using in situ hybridisation, neuronal cell bodies were found to contain VIP (fig $4 \mathrm{~A}-\mathrm{D}$ ), galanin (fig $4 \mathrm{E}-\mathrm{H}$ ), NPY, CGRP, and nNOS mRNA.

The distribution pattern of nerve fibres in ileum of sham operated rats was identical to that previously described for the normal rat. ${ }^{12-14}{ }^{23}$ Numerous VIP, NPY, galanin, and SP containing nerve fibres were found in all layers of the ileal wall, while PACAP, CGRP, and GRP containing ones were slightly less frequent. NADPH diaphorase positive and nNOS immunoreactive nerve fibres were almost exclusively found within the smooth muscle, particularly the deep muscular plexus, and in myenteric ganglia, where they were numerous. The topographic distribution of the various nerve fibre populations in bypassed ileum (one, four, and 10 weeks) was identical to that of the sham operated although the density of the various nerve fibres was gradually increased throughout the time course studied. This is probably due to the reduced volume (as measured by a decreased circumference) of the ileum. Cell counting revealed that the total numbers (established by EtBr staining) of both submucous and myenteric neurones per unit length were increased in the ileum bypassed for one and four weeks (fig 2C) compared with sham operated. At 10 weeks after bypass the number of enteric nerve cell bodies per unit length was almost identical to sham operated ileum. The increase in nerve cell bodies per unit length was most pronounced in the myenteric ganglia. Here, in the ileum bypassed for one or four weeks the numbers of neurones per unit length were almost double those of sham operated or 10 weeks bypassed. In order to facilitate comparison between sham operated and bypassed ileal segments the numbers of cell bodies in each of the different neuronal 
populations will, in the following, be referred to as percentage of the total number of cell bodies. Figure 2C presents the numbers of cell bodies (submucous and myenteric) per unit length of each neuronal population in sham operated and bypassed (one, four, and 10 weeks) ileum.

\section{Submucous neurones}

In submucous ganglia of sham operated distal ileum, nerve cell bodies containing immunoreactive VIP or NPY were the most frequent (approximately $40 \%$ of total) followed by cell bodies containing PACAP, CGRP, or GRP (approximately $10 \%$ of total); SP, galanin, and nNOS immunoreactive cell bodies were few (less than $5 \%$ of total) (fig $5 \mathrm{~A}$ ). On the whole, in situ hybridisation for VIP, NPY, galanin, CGRP, and nNOS mRNA gave similar results showing VIP and NPY mRNA in numerous submucous cell bodies while CGRP mRNA, galanin mRNA, and nNOS mRNA were expressed in smaller populations (fig 5B). In bypassed ileum the percentage of both VIP and NPY immunoreactive cell bodies gradually decreased (fig 5A) as did the number of VIP and NPY mRNA expressing submucous neurones (fig 5B). The decrease in both VIP and NPY immunoreactive submucous cell bodies was maximal after four weeks of bypass (to $14.3(1.6) \%$ and 9.0 (1.0)\%, respectively of total). After four weeks no further decrease in VIP or NPY immunoreactive submucous neurones could be noted. A decreased number of
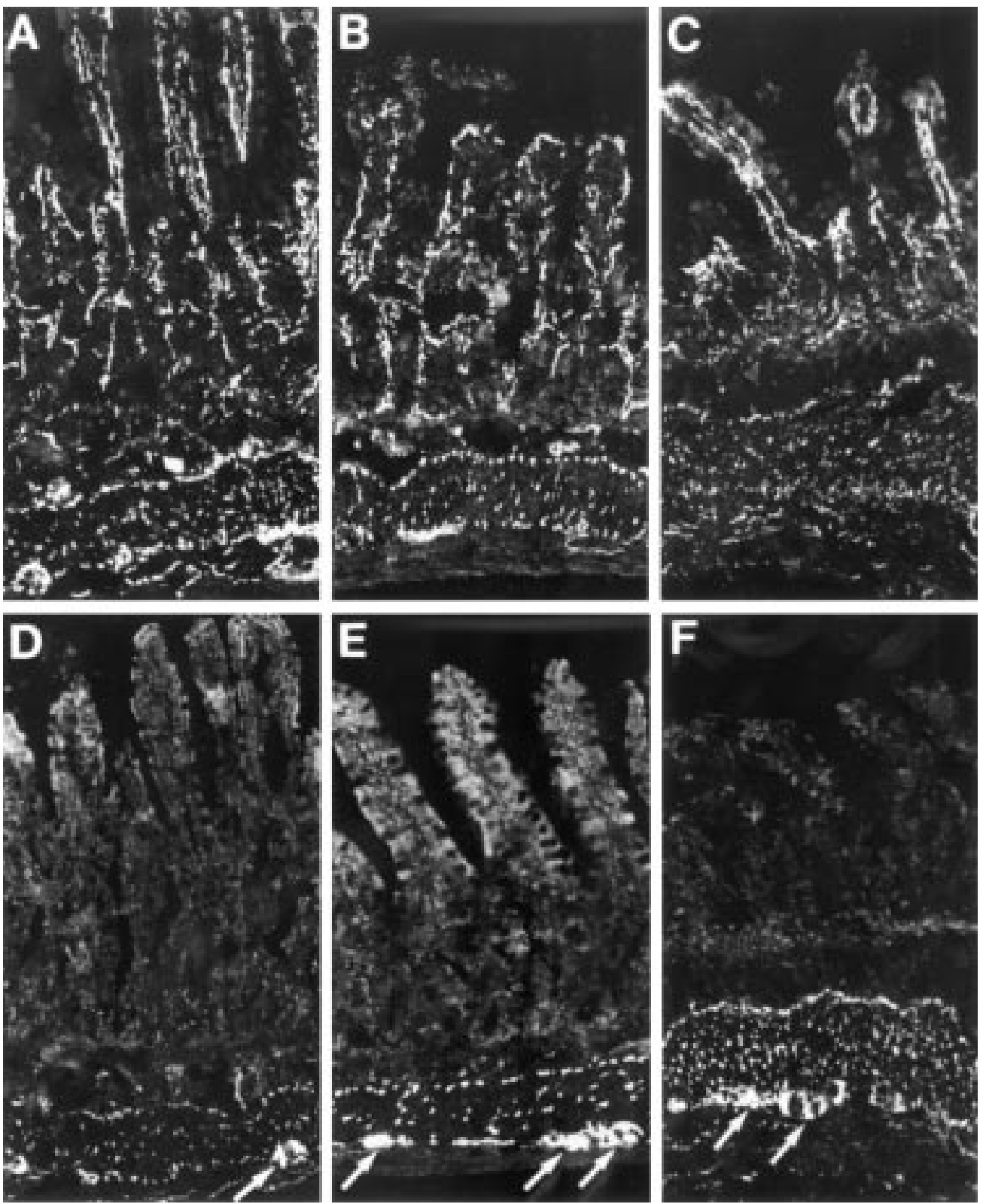

Figure 3 Cryostat sections from rat, sham operated ( $A$ and $D$ ), one week ( $B$ and $E$ ), and 10 weeks ( $C$ and $F$ ) bypassed ileum, immunostained for VIP $(A-C)$ and $n N O S(D-F)$. VIP immunoreactive nerve fibres are numerous in mucosa/submucosa, muscular layers, and enteric ganglia at all time points studied. nNOS immunoreactive nerve fibres are restricted to the muscle layers and myenteric ganglia. The number of nNOS immunoreactive cell bodies within myenteric ganglia (indicated by arrows) is increased in bypassed ileum, particularly 10 weeks postoperatively (F). Original magnification $\times 130$. 
neurones immunoreactive to PACAP could also be noted (fig 5A). The decrease in PACAP immunoreactive neurones was maximal at one week (from $11.8(1.2) \%$ to $3.1(0.7) \%$ of total). The numbers of nNOS immunoreactive as well as NADPH diaphorase positive cell bodies increased, as did the numbers of nNOS mRNA labelled cell bodies. The remainder of the neuronal populations within the submucous ganglia showed no obvious changes in their numbers (fig 5A).

Myenteric ganglia

In myenteric ganglia from the distal ileum of sham operated rats nNOS immunoreactive and NADPH diaphorase positive cell bodies were
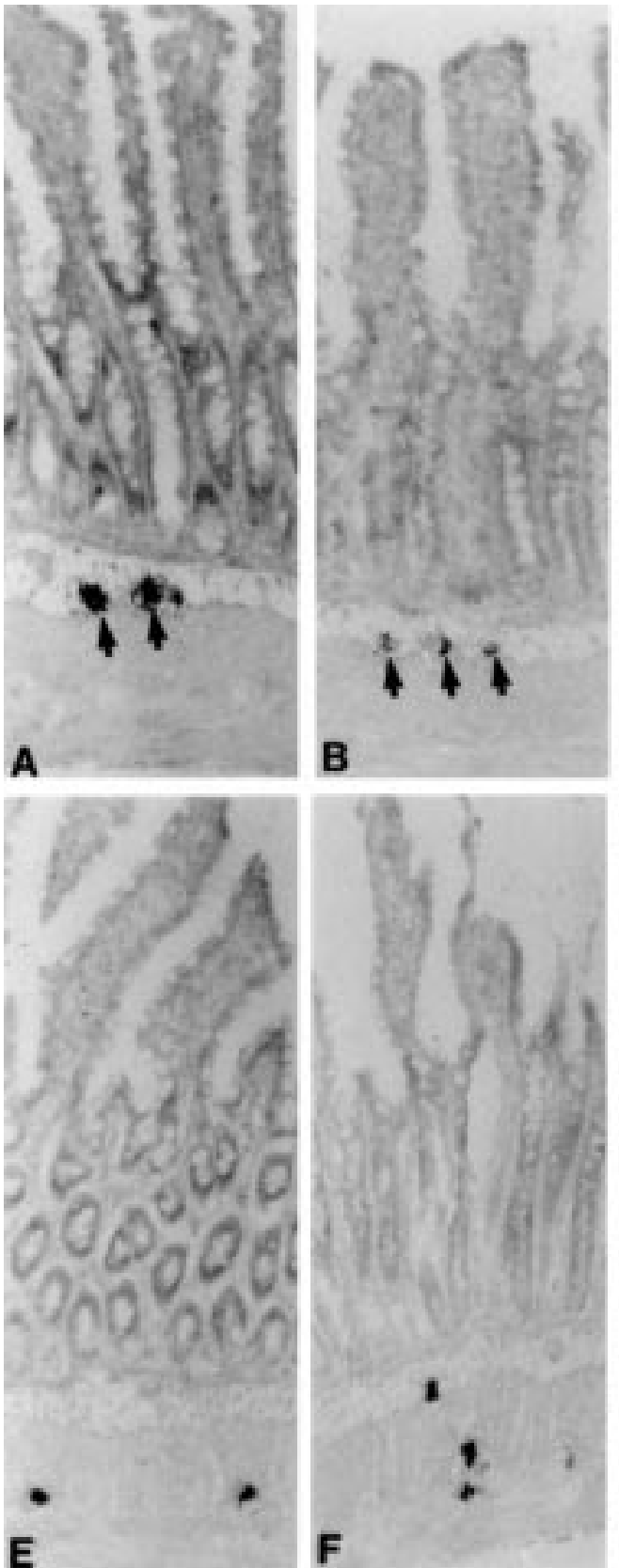

Figure 4 Cryostat sections from rat, sham operated ( $A$ and $E$ ), one week ( $B$ and $F$ ), four weeks ( $C$ and $G$ ), and 10 weeks $(D$ and $H$ ) bypassed ileum autoradiographically labelled for VIP $m R N A(A-D)$ and galanin $m R N A(E-H)$. VIP $m R N A$ containing submucous neurones (indicated by arrows) are intensely labelled in sham operated ileum $(A)$ but only weakly labelled in the bypassed ileum $(B-D)$. The labelling of galanin $m R N A$ containing enteric neurones is equally intense in both sham operated $(E)$ and bypassed $(F-H)$ ileum. Original magnification $\times 130$. the most frequently occurring neuronal population (approximately $30 \%$ of total); the remainder of the neuronal populations each constituted less than $10 \%$ of the total number as studied by immunocytochemistry (fig $5 \mathrm{C}$ ). With the exception of galanin, in situ hybridisation gave similar figures; the percentage of nNOS mRNA expressing myenteric neurones was 33.3 (2.3)\% while VIP mRNA, CGRP mRNA, and NPY mRNA expressing myenteric nerve cell bodies was less than $10 \%$ (fig 5D). The number of myenteric neurones expressing galanin mRNA was $18.6(1.7) \%$ of the total while the number of galanin immunoreactive nerve cell bodies was $3.2(0.8) \%$. After bypassing the distal ileum the numbers of nNOS
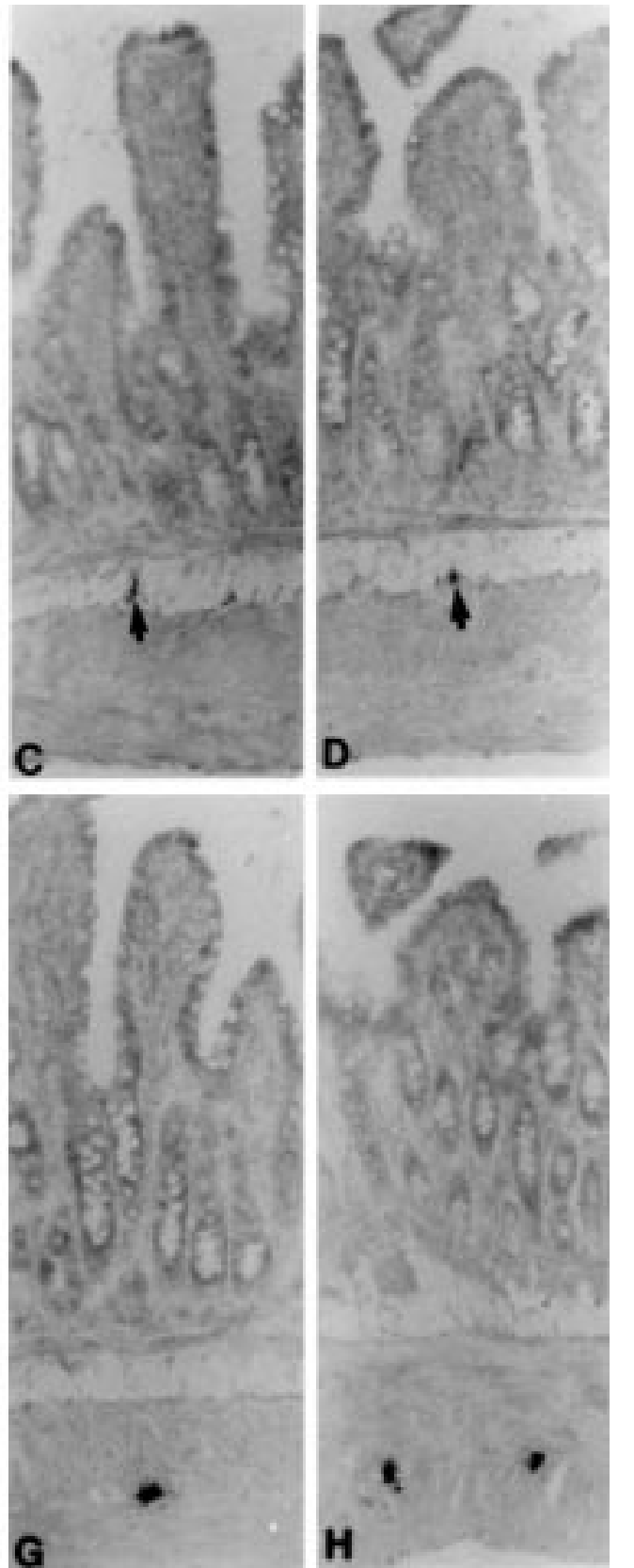
containing, NADPH diaphorase positive, and nNOS mRNA expressing myenteric neurones increased notably. The most pronounced increase was found between four and 10 weeks (fig 5C, D). VIP and NPY expressing myenteric neurones decreased in number as did the PACAP immunoreactive neurones. Galanin and CGRP mRNA expressing neurones decreased slightly after bypass; however, the numbers of galanin and CGRP immunoreactive neurones were unaffected. The remainder of the myenteric neuronal populations remained largely unaffected (fig 5C, D).

\section{Interstitial cells of Cajal}

In both sham operated and bypassed (one, four, or 10 weeks) rat ileum numerous ICC were visualised, by the c-kit antibodies, within the deep muscular plexus of the circular muscle and between the circular and longitudinal muscle layers (fig 6). A few ICC were also found intramuscularly, particularly within the circular muscle. The ICC were small with multiple extensions in various directions. No overt differences in the distribution or frequency of ICC could be noted in bypassed (1-10 weeks) (fig 6B,C) compared with the distal ileum from sham operated rats (fig $6 \mathrm{~A})$.
MOTOR ACTIVITY

Sham operated ileum

In the ileal strips from sham operated rats EFS resulted in a biphasic contraction: a fast twitch that could be abolished by atropine $\left(10^{-6} \mathrm{M}\right)$ pretreatment and a slower contraction not blocked by atropine $(n=12)$ (fig 7$)$. EFS of atropine pretreated and $\mathrm{PGF}_{2 \alpha}$ precontracted strips caused a biphasic response: a relaxation followed by a contraction. The amplitude of the relaxations was reduced to $33(7) \%(n=16)$ of control after pretreatment with L-NAME $\left(10^{-4} \mathrm{M}\right)$; no effect on the contractions could be noted (fig 7). Reactive blue 2 did not cause any change in the relaxatory or contractile responses $(n=8)$ (not shown).

\section{Bypassed ileum}

In strips from ileum bypassed for one week EFS resulted in a triphasic response: an initial relaxation followed by a biphasic contraction (fig 7). Atropine pretreatment caused no change of this triphasic response $(n=12)$. EFS of atropine pretreated and $\mathrm{PGF}_{2 \alpha}$ precontracted strips from bypassed (one week) ileum caused a biphasic response: a relaxation followed by a contraction, resembling that of the sham operated. However, the relaxation was only weakly affected by L-NAME pretreatment: inhibition to $79(5) \%$ of control $(n=12)$
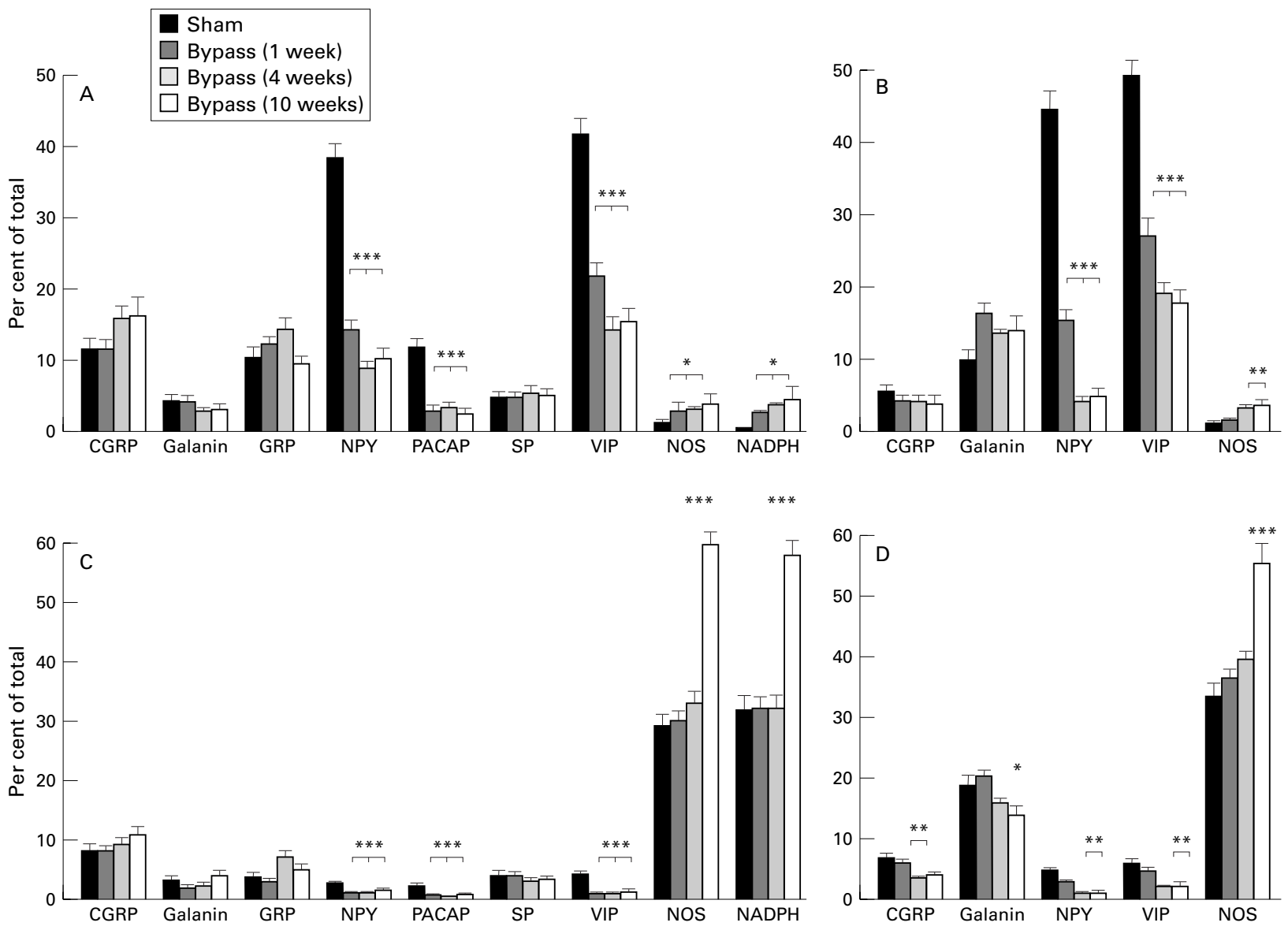

Figure 5 Numbers of CGRP, galanin, GRP, NPY, PACAP, SP, VIP, and nNOS immunoreactive, NADPH diaphorase positive (A and C); and CGRP $m R N A$, galanin $m R N A, N P Y m R N A$, VIP $m R N A$, and $n N O S m R N A$ expressing $(B$ and $D)$ neuronal cell bodies in submucous $(A$ and $B)$ and myenteric (C and $D)$ ganglia from sham operated and bypassed (1-10 weeks) rat ileum. The numbers of positive cell bodies are expressed as the percentage of the total number of cell bodies, established by EtBr staining. Mean (SEM). ${ }^{*}<<0.05,{ }^{*} p<0.01,{ }^{\star} * \star_{p}<0.001$ compared with sham operated; $p$ values refer to one, two, or three bars, as indicated. 

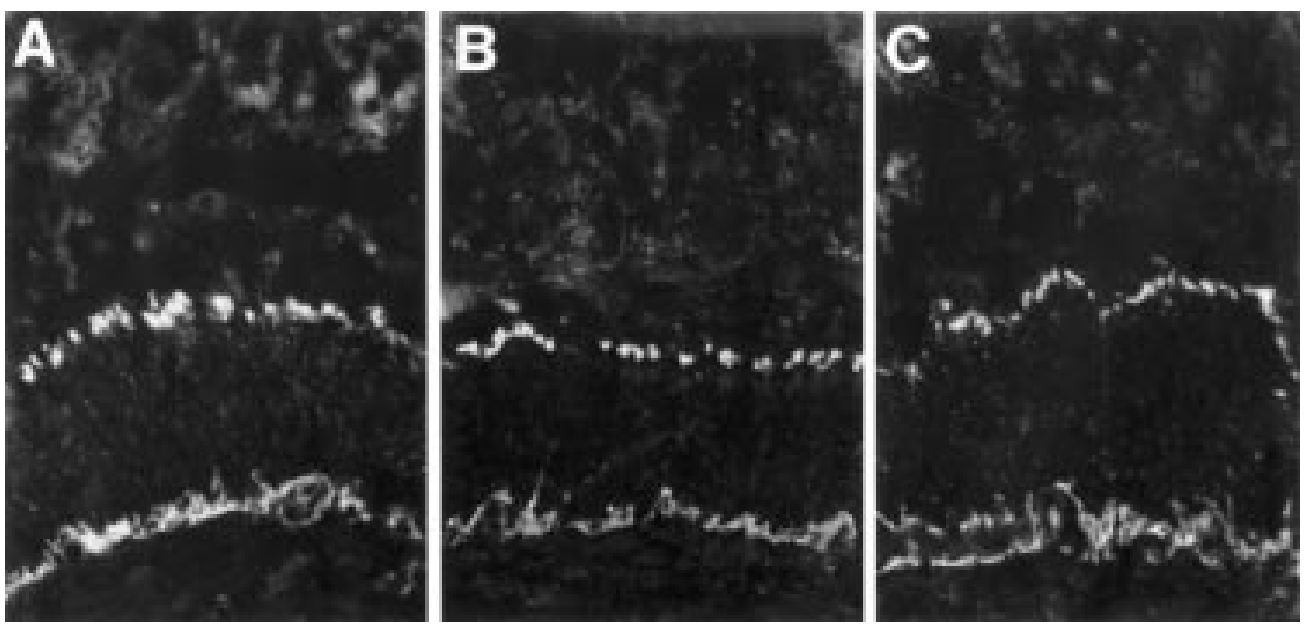

Figure 6 Cryostat sections from rat: $(A)$ sham operated, $(B)$ one week, and $(C) 10$ weeks bypassed ileum, showing the presence of ICC using antiserum against c-kit receptor. Numerous ICC are found within the deep muscular plexus and at the border of longitudinal and circular muscle in both sham operated and bypassed ileum. Original magnification $\times 180$.

(fig 7). The EFS evoked responses on ileal strips after four or 10 weeks of bypass were essentially similar to those after one week of bypass (fig 7). L-NAME pretreatment caused, however, no inhibition of the relaxatory responses (four weeks: 95 (5)\% of control, $\mathrm{n}=13$; 10 weeks: 96 (12)\% of control, $\mathrm{n}=10$; fig 7 ). Reactive blue 2 was ineffective in blocking any of the components of the EFS induced motor responses in bypassed (1-10 weeks, $\mathrm{n}=10$ ) ileum (not shown).

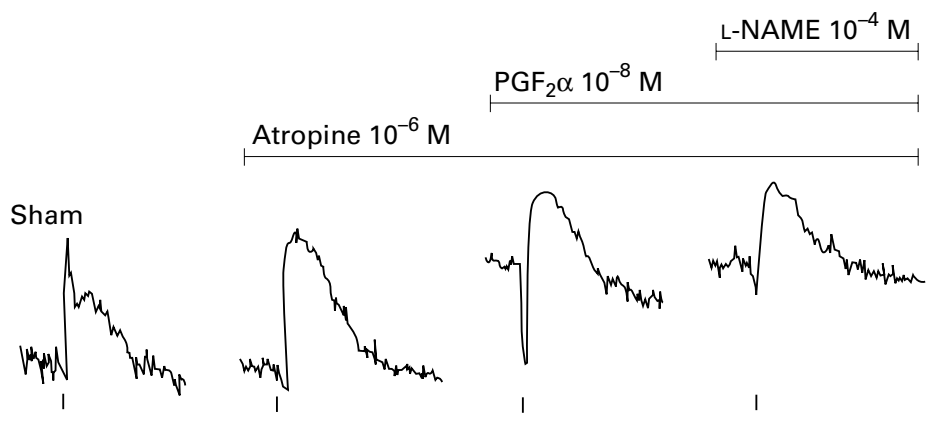

Bypass 1 week

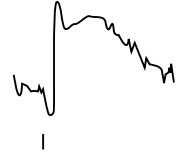

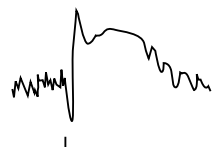<smiles>CC1CCCCC1I</smiles>

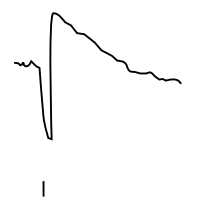

Bypass 4 weeks
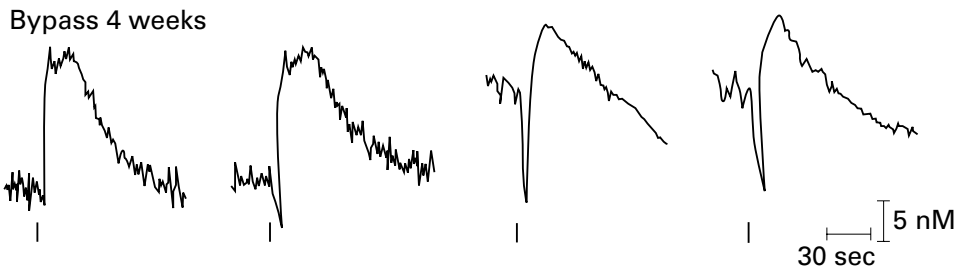

Figure 7 Tracings of electrically induced responses of rat sham operated, one week, and four weeks bypassed ileum. Stimulation $(20 \mathrm{~Hz}, 4 \mathrm{~V}, 400 \mathrm{~mA})$ was maintained for five seconds (indicated by vertical bars). The contractile response elicited by electrical stimulation of sham operated ileum consists of a fast cholinergic twitch followed by a slower non-adrenergic, non-cholinergic (NANC) mediated contraction; in the bypassed ileum an identical biphasic contraction is elicited; however, the entire response was NANC mediated - that is, not blocked by atropine. After precontraction by PGF and in the presence of atropine a relaxation followed by a contraction is elicited by EFS. The EFS induced relaxatory response in sham operated ileum is abolished by L-NAME and thus, NO mediated. After bypass the relaxation was unaffected by pretreatment with L-NAME.

\section{Discussion}

The structural changes occurring in defunctional ileum after bypass involve atrophy of the intestinal segment. This was mainly reflected in a reduced circumference, while the whole wall thickness remained remarkably stable throughout the observation period; a slight decrease occurred in the first week after bypass but no further reduction could be noted at four or 10 weeks. However, a remodelling of the ileal wall occurred gradually after bypass. The mucosal layer became thinner while the muscular layers and the submucosa increased in thickness. The number of enteric neurones, particularly the myenteric ones, increased after one and four weeks of bypass as counted per unit length. This is probably a result of the reduced volume of the remainder of the bypassed intestinal wall leading to a condensation of ganglia due to loss of surrounding tissue. After 10 weeks of bypass the number of enteric neurones per unit length resembled that of intact (sham operated) intestine suggesting that cell death of enteric neurones has occurred. The cell death of enteric neurones as well as of other cells of the bypassed intestinal segment, is probably mediated through programmed cell death (apoptosis), as the surgical procedures in creating the bypass or the subsequent atrophic changes do not involve any inflammation or major insults resulting in necrosis. Apoptosis is an important physiological process in the regulation of gastrointestinal mucosa (for a review see Jones and Gores $^{24}$ ). In normal intestine apoptosis is suggested to be responsible for the shedding of cells from the villus tips and a number of factors such as transforming growth factor $\beta$ and NO but also fermentation products from dietary fibres are mediators of apoptosis. Inhibitors of apoptosis include epidermal growth factor and transforming growth factor $\alpha$. No information is available on apoptosis of intestinal smooth muscle or enteric neurones. Our own preliminary studies on sections from bypassed (1-10 weeks) ileum of rats using the TUNEL (terminal deoxynucleotidyl transferase mediated dUTP-biotin nick end 
labelling) assay revealed a prompt increase in the number of labelled cells in the mucosa, particularly in the villus tips compared with normal or sham operated rat ileum, while no positive cells were detected within the smooth muscle or enteric ganglia. This indicates that apoptosis contributes to the atrophic changes noted in the defunctional bypassed ileum. Our failure in detecting apoptotic cells in the smooth muscle or nervous tissue may be explained by the fact that apoptosis occurs rapidly in vivo ${ }^{24}$ and may therefore be difficult to detect in histological sections. Furthermore, the TUNEL assay may not be sensitive enough and other means of detecting apoptotic cells are currently being investigated.

The ENS can be divided in different subpopulations on the basis of their content of different neurotransmitters or markers. ${ }^{25}{ }^{26}$ Cell counting revealed that adaptive changes in the proportions of the different neuronal populations occur as a result of intestinal defunction after bypass. Such adaptive changes may be the result of several factors: atrophy is one, changes in the luminal milieu (loss of luminal factors or a change in the intestinal flora) are other possible factors. In both the submucous and myenteric ganglia in bypassed ileum the main change was a reduced number of neurones expressing VIP, NPY, or PACAP while the number of nNOS expressing neurones increased. The increase in nNOS expressing neurones was most pronounced in the myenteric ganglia; here an almost twofold increase was noted. These changes may be explained by a general reduction of the enteric neurones and neuronal plasticity involving downregulation of VIP, NPY, and PACAP mRNA with a simultaneous upregulation of nNOS mRNA. It may also be explained by selective apoptosis of some of the neurones (those expressing VIP, NPY, and PACAP) while the nNOS expressing ones are spared, or by a combination of these events. The mechanisms behind the neuronal cell death, general or selective, can only be speculated on; lack of target derived nerve growth factors due to the atrophic changes in the gut wall may provide one explanation. The reduced expression of VIP and PACAP in enteric neurones presumably plays a crucial role as both peptides support neuronal development and survival. ${ }^{27}{ }^{28}$ Notable is that upregulation of VIP in enteric neurones occurs after axotomy or axonal transport blockade by colchicine $^{19}$ and that hypertrophic changes in rat ileum upregulate the expression of VIP and PACAP in enteric neurones. ${ }^{5}$ Selective neuronal cell death of enteric neurones may be due to apoptotic signals probably involving the release of NO. In the central nervous system NO is a major mediator of neural damage in conditions such as stroke or Parkinson's disease. ${ }^{29}{ }^{30} \mathrm{Neu}-$ ronal cell death has been suggested to be mediated through the generation of free radical NO followed by peroxynitrite formation. ${ }^{31}$ nNOS expressing neurones themselves have been reported to be selectively resistant to the degenerative changes caused by NO cytotoxicity in conditions such as Huntington's chorea or Alzheimer's disease but also after ischaemia. ${ }^{29}$ It is of interest to note that neuronal cell death of enteric neurones occurs in the atrophic ileum, as reported in the present study, but that nNOS expressing neurones are spared in analogy with several neurodegenerative diseases in the central nervous system. Likewise, ageing results in loss of myenteric neurones ${ }^{32}$ accompanied by a relative increase in the number of nNOS containing neurones. ${ }^{33}$ Taken together these observations indicate that neuronal plasticity in terms of changes in the expression of neurotransmitters is a common adaptive phenomenon in the intestine and that neurodegeneration within the ENS may contribute. The insight that ENS may play a significant role in intestinal adaptation highlights the necessity of investigating neuronal plasticity in various forms of intestinal dysfunction. Few such studies have been undertaken; however, a recent study ${ }^{34}$ on patients with Crohn's disease reports on a notable increase in the numbers of VIP, PACAP, and NPY immunoreactive myenteric neurones in the small intestine.

The present study also reports on a remarkable functional adaptation in bypassed ileum. Although the motor responses to electrical stimulation in sham operated and bypassed ileum were essentially identical, different sets of neurotransmitters seem to operate as mediators after bypass. The contractile response elicited by EFS of the ileum from sham operated rats consisted of a fast cholinergic twitch followed by a slower non-adrenergic, noncholinergic (NANC) contraction. In the bypassed ileum an identical biphasic contraction was elicited; however, the entire response was NANC mediated. Which NANC mediator substitutes for acetylcholine is unknown as is the NANC mediator(s) of the second, slow phase of the contractile response. Furthermore, the relaxatory responses to EFS in sham operated and bypassed ileum were identical. However, in the sham operated (as in normal rat ileum ${ }^{35}$ ) the relaxation was to a large extent (approximately 70\%) blocked by L-NAME and thus probably mediated by release of $\mathrm{NO}$, while in the bypassed ileum the portion of the relaxatory response mediated by $\mathrm{NO}$ release gradually diminished, being only approximately $5 \%$ after four weeks of bypass. The relaxatory mediator(s) that substitutes for $\mathrm{NO}$ is unknown. One possible candidate is adenosine triphosphate (ATP) but reactive blue 2, a blocker of $\mathrm{P}_{2 \mathrm{y}}$ receptors, ${ }^{36}$ did not reduce the amplitude of the relaxation. Thus, ATP can probably be excluded as a candidate. Other possible candidates are the potent inhibitory neuropeptides VIP and PACAP. Although the synthesis of these peptides is downregulated in bypassed ileum, as shown in the present paper, their receptors may be upregulated. In fact supersensitivity to both of these peptides has been reported in bypassed rat ileum. ${ }^{37}$ The finding that an identical stimulus generated essentially identical responses in terms of contractions and relaxations but that these responses were, at least in part, mediated by different neurotransmitters indicates that neurotransmitters are interchangeable and that 
they can substitute for each other. The reasons, beneficial or not, for the bypassed ileum not to utilise acetylcholine and NO as transmitters are enigmatic. Downregulation of muscarinic receptors may explain the shift of the cholinergic contraction to one that is NANC mediated. Such downregulation has been implicated after massive intestinal resection ${ }^{38}$ or intestinal transplantation $^{39}$ and a subsensitivity to acetylcholine has been noted in bypassed ileum (own unpublished results). A downregulation of muscarinic receptors may also be reflected in a failure to release neuronal $\mathrm{NO}$ as acetylcholine was found to release $\mathrm{NO}$ as studied in rat colon. ${ }^{40}$ Given that the adaptive neuronal cell death in bypassed ileum reported in the present study is NO mediated, a shift of the role of NO as a relaxatory mediator to a cytotoxic mediator in atrophic gut may be necessitated.

In conclusion, notable adaptive changes are seen within the atrophic ileal wall. Such changes include atrophy and remodelling of the gut wall. The ENS reacts with neuronal cell death and plasticity in terms of release and expression of neurotransmitters. Both submucous and myenteric neurones expressing VIP, NPY, and PACAP were reduced in number while NOS expressing neurones increased, particularly in the myenteric ganglia. No change in the frequency and distribution of ICC was noted. The contractile response elicited by electrical stimulation of sham operated ileum consisted of a fast cholinergic twitch followed by a slower NANC mediated contraction. In the bypassed ileum an identical biphasic contraction was elicited; however, the entire response was NANC mediated. The relaxatory response to electrical stimulation in sham operated ileum was NO mediated while it was non-nitrergic after bypass.

This work was funded by the Swedish Medical Research Council (project no 12X-4499), Påhlsson, Wiberg, Julin, and Crafoord Foundations.

1 Dowling RH. Cellular and molecular basis of intestinal and pancreatic adaptation. Scand $\mathcal{F}$ Gastroenterol 1992;193:64pan

7

Wolvekamp MC, Heineman E, Taylor RG, et al. Towards understanding the process of intestinal adaptation. Dig Dis 1996;14:59-72.

3 Gabella G. Hypertrophy of intestinal smooth muscle. Cell Tissue Res 1975;163:199-214.

4 Gabella G. Hypertrophy of visceral smooth muscle. Anat Embryol 1990;182:409-24.

5 Ekblad E, Sjuve R, Arner A, et al. Enteric neuronal plasticity and a reduced number of interstitial cells of Cajal in hypertrophic rat ileum. Gut 1998;42:836-44

6 Schultze-Delrieu K, Brown B, Herman B, et al. Preservation of peristaltic reflex in hypertrophied ileum of guinea pig. Am $\mathcal{F}$ Physiol 1995;269:G49-59.

7 Vanderhoof JA, Langnas AN. Short-bowel syndrome in children and adults. Gastroenterology 1997;113:1767-78.

8 Buchman AL, Moukarzel AA, Amen ME, et al. Effects of total parenteral nutrition on intestinal morphology and fotal parenteral nutrition on intestinal morphology in humans. Transplant Proc 1994;26:1457.

9 Kissmeyer-Nielsen P, Christensen H, Laurberg S. Diverting colostomy induces mucosal and muscular atrophy in rat colostomy induces mucosal and mus
distal colon. Gut 1994;35:1275-81.

10 Gavazzi I, Cowen T. Can the neurotrophic hypothesis explain degeneration and loss of plasticity in mature and ageing autonomic nerves? F Autonom Nerv Syst 1996,58:110 .

11 Ekblad E, Winther C, Ekman R, et al. Projections of peptide-containing neurones in rat small intestine. Neuroscience 1987;20:169-88.
12 Ekblad E, Ekman R, Håkanson R, et al. Projections of peptide-containing neurones in rat colon. Neuroscience 1988:27:655-74.

13 Ekblad E, Alm P, Sundler F. Distribution, origin and projections of nitric oxide synthase-containing neurones in gut and pancreas. Neuroscience 1994;63:233-48.

14 Sundler F, Ekblad E, Absood A, et al. Pituitary adenylate cyclase activating peptide: a novel vasoactive intestinal peptide-like neuropeptide in the gut. Neuroscience 1992;46: 439-54.

15 Bredt DS, Hwang PM, Glatt CE, et al. Cloned and expressed nitric oxide synthase structurally resembles cytochrome P-450 reductase. Nature 1991;351:714-18.

16 Nishizawa M, Hayakawa Y, Yanaihara N, et al. Nucleotide sequence divergence and functional constraint in VIP precursor mRNA evolution between human and rat. FEBS Lett 1985;183:55-9.

17 Larhammar D, Ericsson A, Persson H. Structure and expression of the rat neuropeptide Y gene. Proc Natl Acad Sci USA 1987;84:2068-72.

18 Kaplan LM, Spindel ER, Isselbacher KJ, et al. Tissuespecific expression of the rat galanin gene. Proc Natl Acad Sci USA 1988;85:1065-9.

19 Ekblad E, Mulder H, Sundler F. Vasoactive intestinal peptide expression in enteric neurones is upregulated by both colchicine and axotomy. Regul Pept 1996;63:113-21.

20 Mulder H, Uddman R, Moller K, et al. Pituitary adenylate cyclase activating polypeptide (PACAP) expression in sensory neurones. Neuroscience 1994;63:307-12.

21 Hope B, Michael GJ, Knigge KM, et al. Neuronal NADPH diaphorase is a nitric oxide synthase. Proc Natl Acad Sci USA 1991;88:2811-14.

22 Schmued LC, Swanson LW, Sawchenko PE. Some fluorescent counterstains for neuroanatomical studies. $\mathcal{F}$ Histochem Cytochem 1982;30:123-8.

23 Ekblad E, Håkanson R, Rökaeus Å, et al. Galanin nerve fibres in the rat gut: distribution, origin and projections. Neuroscience 1985;16:355-63.

24 Jones BA, Gores GJ. Physiology and pathophysiology of apoptosis in epithelial cells of the liver, pancreas, and intestine. Am f Physiol 1997;273:G1 174-88.

25 Ekblad E, Håkanson R, Sundler F. Microanatomy and chemical coding of peptide-containing neurones in the digestive tract. In: EE Daniel, ed. Neuropeptide function in the gastrointestinal tract. Boca Raton, FL: CRC Press, 1991: the gastroint 79 .

26 Furness JB, Young HM, Pompolo S, et al. Plurichemical transmission and chemical coding of neurones in the digestive tract. Gastroenterology 1995;108:554-63.

27 Brenneman DE, Eiden LE. Vasoactive intestinal peptide and electrical activity influence neuronal survival. Proc Natl Acad Sci USA 1986;73:1159-62.

28 Tanaka J, Koshimura K, Murakami Y, et al. Stimulatory effect of PACAP on neuronal cell survival. Ann NY Acad Sci 1996;805:473-5.

29 Moncada S, Palmer RMJ, Higgs EA. Nitric oxide: physiology, pathology and pharmacology. Pharmacol Rev 1991;443:109-42.

30 Jaffrey SR, Snyder SH. Nitric oxide: a neural messenger. Ann Rev Cell Dev Biol 1995;11:417-40.

31 Dawson VL, Dawson TM. Nitric oxide neurotoxicity. $\mathcal{f}$ Chem Neuroanat 1996;10:179-90.

32 Santer RM, Baker DM. Enteric neuron numbers and sizes in Auerbach's plexus in the small and large intestine of adult and aged rats. F Auton Nerv Syst 1988;25:59-67.

33 Belai A, Cooper S, Burnstock G. Effect of age on NADPHdiaphorase-containing myenteric neurons of rat ileum and proximal colon. Cell Tissue Res 1995;279:379-83.

34 Belai A, Boulos PB, Robson T, et al. Neurochemical coding in the small intestine of patients with Crohn's disease. Gut 1997;40:767-74

35 Ekblad E, Sundler F. Motor responses in rat ileum evoked by nitric oxide donors vs. field stimulation: modulation by pituitary adenylate cyclase-activating peptide, forskolin and guanylate cyclase inhibitors. F Pharm Exp Ther 1997;283: $23-8$.

36 Soediono P, Burnstock G. Contribution of ATP and nitric oxide to NANC inhibitory transmission in rat pyloric sphincter. Br F Pharmacol 1994;113:681-6.

37 Ekblad E, Ekelund M, Sundler F. Relaxant responses of VIP and PACAP in rat ileum: receptors and adaptive supersensitivity. Ann NY Acad Sci 1998;865:393-7.

38 Chin BC, Tan DTM, Scott RB. Depressed smooth muscle contractility after massive intestinal resection in rat: role of alterations in muscarinic receptor status or source of calcium for excitation-contraction coupling. Can $\mathcal{F}$ Physiol Pharmacol 1996;74:1187-95.

39 Zhang Z, Koch TR, Mustin E, et al. Muscarinic cholinergic receptor density following small intestinal transplantation in rats. Am f Physiol 1993;265:G1057-63.

40 Iversen $\mathrm{HH}$, Wiklund NP, Olgart C, et al. Nerve stimulation-induced nitric oxide release as a consequence of muscarinic M1 receptor stimulation. Eur $\mathcal{F}$ Pharmacol 1997;331:213-19. 